\title{
Psychophysical measures of visual function and everyday perceptual experience in a case of congenital stationary night blindness
}

This article was published in the following Dove Press journal:

Clinical Ophthalmology

22 August 2016

Number of times this article has been viewed

\author{
Jocelyn Cammack' \\ John Whight ${ }^{2}$ \\ Vinette Cross ${ }^{3}$ \\ Andrew T Rider ${ }^{\prime}$ \\ Andrew R Webster ${ }^{1,2}$ \\ Andrew Stockman'
}

'Department of Visual Neuroscience, UCL Institute of Ophthalmology, 2Moorfields Eye Hospital, London, ${ }^{3}$ Centre for Health and Social Care Improvement, University of Wolverhampton, Wolverhampton, UK

Correspondence: Jocelyn Cammack UCL Institute of Ophthalmology,

I I-43 Bath Street,

London ECIV 9EL, UK

Tel +44207608 6914

Fax +44 2076086850

Email j.cammack@ucl.ac.uk
Abstract: An appreciation of the relation between laboratory measures of visual deficit and everyday perceptual experience is fundamental to understanding the impact of a visual condition on patients and so to a fuller characterization of the disorder. This study aims to understand better the interpretative processes by which modified sensory information is perceived by a patient with congenital stationary night blindness and the adaptive strategies that are devised to deal with their measurable visual loss. Psychophysical measurements of temporal resolution, spectral sensitivity, and color discrimination were conducted on a 78-year-old male patient with the condition, who was also interviewed at length about the ways in which his diagnosis affected his daily life. Narrative analysis was employed to identify the relation between his subjective perceptual experiences and functional deficits in identifiable components of the visual system. Psychophysical measurements indicated a complete lack of rod perception and substantially reduced cone sensitivity. Two particular effects of this visual loss emerged during interviews: 1) the development of navigational techniques that relied on light reflections and point sources of light and 2) a reluctance to disclose the extent of visual loss and resulting lifelong psychosocial consequences. This study demonstrates the valuable complementary role that rich descriptive patient testimony can play, in conjunction with laboratory and clinical measurements, in more fully characterizing a disorder and in reaching a more complete understanding of the experience of vision loss. It also evidences the particular suitability of filmmaking techniques as a means of accessing and communicating subjective patient experience.

Keywords: congenital stationary night blindness, GRM6 gene, narrative analysis, perception, psychophysics, quality of life

\section{Introduction}

Visual function can be measured using standard psychophysical techniques that typically vary some characteristic of a precisely defined visual stimulus and measure the effects of that variation on an individual's subjective responses to the stimulus. In comparison with fully sighted people, the results of such techniques reveal that people with specific visual deficits demonstrate characteristic and measurable changes or losses in visual function. ${ }^{1,2}$ The quality of our perceptual experience, although not directly measurable, must be dependent in part on our visual function, but little work has been done on how these measurable visual deficits relate to everyday perceptual experience.

Congenital stationary night blindness (CSNB) is the name given to a family of congenital retinal disorders characterized by an inability to see in low illumination. These disorders, which show limited progression with age, can be caused by mutations in a 
number of genes and can segregate in families in X-linked, autosomal-dominant, and autosomal-recessive forms. ${ }^{3}$ There are at least five recessive genes that have been reported to be associated with a complete CSNB phenotype: $N Y X$, GRM6, TRPM1, GRP179, and LRIT3. ${ }^{4}$ The GRM6 gene, located on chromosome $5 \mathrm{q} 35,{ }^{5,6}$ encodes mGluR6. This receptor is expressed at the ribbon synapses of ON bipolar cell dendrites and mediates synaptic transmission to these second-order neurons from rod and cone photoreceptors. ${ }^{5}$ Mutation of this gene would thus be expected to result in dysfunction of the rod and cone ON bipolar pathways, ${ }^{7}$ and since there is no rod OFF bipolar cell, patients with this mutation should suffer loss of rod vision, despite having working rods. Transmission via rod-cone gap junctions or directly from rods to cone OFF bipolar cells ${ }^{8}$ (the so-called secondary and tertiary rod pathways) is likely to remain unaffected by this form of CSNB. The ON-pathway dysfunction should, however, also affect $\mathrm{S}$-cone signaling, since the primary $\mathrm{S}$-cone pathway is via $\mathrm{ON}$ bipolar to bistratified ganglion cells. ${ }^{9}$

Although the biology of GRM6-related CSNB is relatively well understood, little is known of the effect the condition has on everyday life. The aim of this study was thus to understand better the scope of the visually impaired experiences resulting from this condition, including 1) the interpretative mechanisms by which sensory information is perceived and 2) the subtle and complex adaptive strategies, both behavioral and psychoemotional, that are adopted to deal with the consequences of the condition.

Stories are the interpretative devices through which people represent and make sense of themselves and their lifeworlds (holistic subjective experiences) ${ }^{10}$ and communicate that understanding to others. Documentary filmmaking relies on the generation and acquisition of such stories, through both interview-based and observational filming, to reveal and convey how people understand themselves and their lives. Stories, therefore, constitute the raw material of documentary-filmmaking practices and also of the qualitative methodology of narrative inquiry, ${ }^{11}$ and both approaches were employed in this study to develop a more nuanced insight into a subject's reflexive interpretation of the meaning or functional significance they themselves put on the stories they chose to tell.

In correlating these subjective experiences with measurable visual function, the study provides evidence of the valuable role that rich patient testimony can play, in dialogue with psychophysical and clinical measures, in enabling a more holistic understanding of CSNB.

\section{Subject and methods \\ Recruitment of participant}

JW was selected purposively on the basis of his rare diagnosis and his ability and willingness to articulate the subjective experiences of his condition. JW is a 78-year-old male whose molecular biology had previously revealed biallelic mutations in GRM6 in both himself and his affected sister. ${ }^{12}$ His visual acuity was $6 / 18$ in the right eye and in the left eye was limited to hand-movement detection. In addition to his lifelong myopia, he also had slight nystagmus and myopic degeneration, which in the left eye had caused a choroidal neovascular membrane at the age of approximately 70 years. Fundus images (Figures 1 and 2) of the patient's right eye showed that the foveal structure and retinal pigment epithelium layers remained intact in this eye, which unlike the left eye was not affected by choroidal neovascularization due to myopia. The study was granted ethical approval by the West of Scotland Research Ethics Service (12/WS/0013) and conducted in accordance with the code of ethics of the World Medical Association (Declaration of Helsinki). The participant gave his informed, written consent before taking part in the study.

\section{Data collection}

The characteristics of visual function in JW's right eye were determined using standard psychophysical measures of S- and L-cone temporal acuity (also known as measures of critical flicker-fusion [CFF]), dark-adapted and bleached

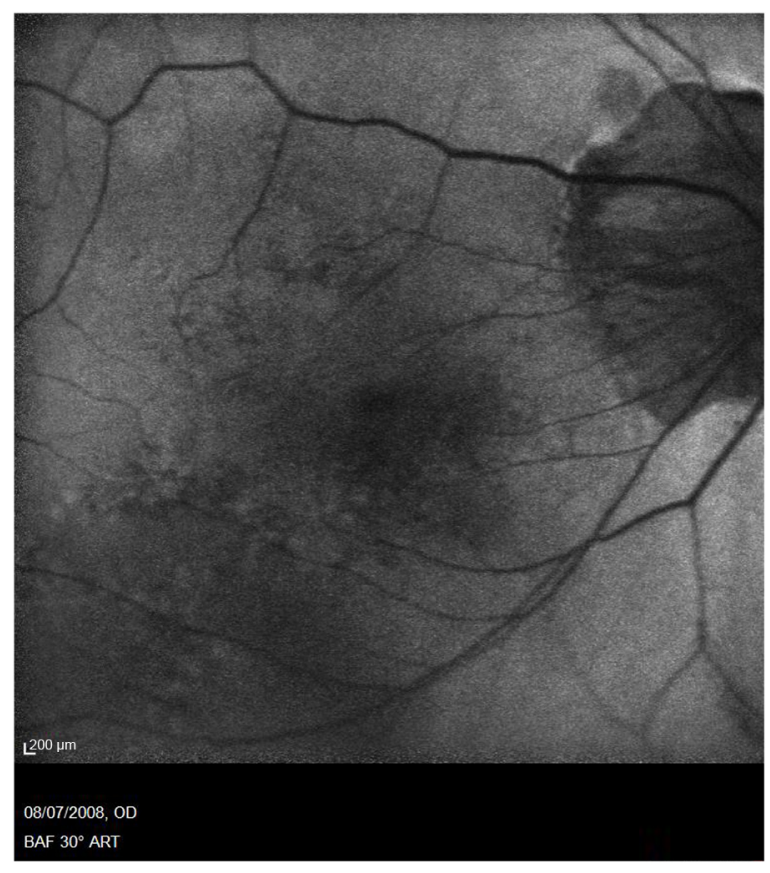

Figure I Autofluorescence image of JW's right eye, 2010. 


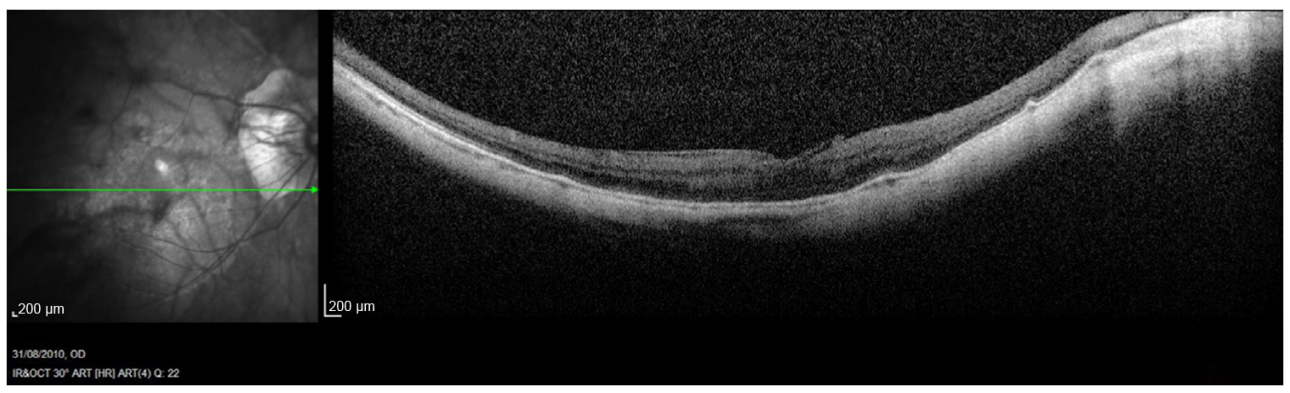

Figure 2 Optical coherence tomography of JW's right eye, 2010.

spectral sensitivities, and color discrimination using the Farnsworth-Munsell 100-hue test. Details of the apparatus and methods employed are presented elsewhere ${ }^{13,14}$ and summarized in Supplementary materials (online). Previous electrophysiological investigations ${ }^{12}$ were consistent with complete CSNB, indicating that JW had functioning rod as well as cone photoreceptors despite being night-blind. His ON-OFF electroretinogram (ERG) results also showed generalized cone ON bipolar system dysfunction, and his rod-specific ERG was undetectable.

Qualitative data were collected primarily through a series of open-ended, in-depth, patient-led interviews conducted face to face at the participant's home. These interviews did not rely on questionnaires and were structured only to the extent that two broad areas of interest were identified beforehand, namely:

1. The phenomenological aspects of the participant's vision and lifeworld, and related to that, his sense-making processes, ie, how he derived meaning from and made use of the visual stimuli he was able to detect

2. the strategies and adaptations employed as a consequence of impaired vision, both practical and psychosocial.

JW was interviewed eight times over a period of 22 months between April 2012 and February 2014, usually for approximately 2 hours, depending on what felt appropriate on that day. Interview questions were open-ended, allowing JW to take the conversation in whatever direction he might choose; he was also free to discontinue a line of thought at any point without giving a reason. The interviewer's own status as a patient with an inherited retinal disorder was made explicit from the outset and seemed to allow JW to talk more freely, due, he said, to a sense that they "would understand". It was this freedom to speak within a trusting and transparent context that allowed the study to access as true a picture as possible of the impact of his visual deficit on the way he lived.

At JW's suggestion, the interview process worked chronologically through his life. Many of his accounts had not previously been articulated and sometimes were not easily told, so he would often initially focus on descriptive accounts of incidents and events. Careful listening facilitated the revisiting of certain points that suggested themselves to be more significant to JW than at first appeared, thereby allowing him to consider the effect these events had had on him at the time and to reflect on how his perspective and thinking on them may have changed since. This in-depth, reflexive interviewing technique, which is often used within nursing and psychosocial research, ${ }^{15,16}$ focused on generating thick, rich testimony of personal subjective experience rather than on any concern with quantitative measures, such as the frequency of occurrence of a particular word within a transcript. Documentary interviewing, which inherently creates opportunities for the interviewee to rephrase their ideas so as to allow the material to be edited to different lengths, may artificially increase the frequency of keywords and key themes. However, as comparison between participants was not the focus of this research, frequency measures and the associated establishment of a coding framework were not appropriate. Field notes and memos, which were produced immediately after each interview and frequently during reading and coding of transcripts, also informed subsequent interview questions and vice versa. In addition, observational footage was shot of JW doing daily tasks, such as working at his computer or preparing a snack. His opinion on the interview process and on our understanding of his contributions was encouraged as the study progressed, and he was also invited to provide feedback on final edits of findings for formal presentation, including this text.

\section{Analysis}

The primary analytic strategy used Transana software ${ }^{17}$ to identify stories from verbatim transcripts of the interview material through a process of open coding. Stories were considered to be recollections through which JW could convey and make sense of his experience of his impaired vision, 
and coding was carried out by adopting an experiential lens through which to interpret his experience. During the ongoing interview process and parallel coding, several themes began to emerge through the identification and paradigmatic analysis ${ }^{11}$ of the stories that JW told. These are summarized in Table 1.

The filmed footage was also edited into sequences (using Final Cut Pro editing software), based on the individual stories that related to or illustrated these themes. This process, which has strong parallels with narrative analysis, ${ }^{11,18}$ informed and supplemented the paradigmatic coding and story-identification process.

Periodically during the study, the emerging themes were discussed with JW as an integral part of checking and clarifying our understanding of the meaning of the material for him, and themes thus continued to develop throughout the study in response to the shifting significance for JW of individual stories. The categorizing of these stories was a similarly fluid process, and "saturation" (the generation of sufficient data) was considered to be the point when JW judged that he

Table I Themes identified in JW's account

Theme
Perceptions of self
Sense of self/personal identity in the world
both privately and in relation to friends/
colleagues and society at large

\section{Attitudes of others}

Perceived attitudes of others toward the subject and/or their condition/disability

\section{Life strategies}

Thoughts on how to cope with vision loss

\section{Practical strategies for seeing} Behavioral habits developed to compensate for reduced vision

\section{Summary of JW's experience in relation to themes}

JW's fear of the consequences of disclosure has had a profound impact on his self-confidence in situations that involve low light levels. Since many social activities are conducted in the evenings, the curtailment of his social life was profound from childhood. Many social situations prompted an acute self-consciousness, for example:

- needing to rely on other boys to make his way to the dormitory after school during the winter months; this would either involve riding his bike behind someone with a good light or walking in the middle of a group

- not being able to engage in conversation about the night stars with a girl during a date, as he could see none of them

- being afraid of walking into the river during a late walk along the River Cam with friends (Table 4A)

- being unable to find his seat during a date at the cinema (Table 4B and Video 2).

His resulting reticence was compensated for through sporting prowess, mainly as a cricketer, cricket being an activity for which "bad light stops play".

As a youngster, JW knew that he was regarded as one of the "quiet boys". Later in life he felt colleagues perceived him as self-important, superior, or unsociable as a result of being unable to acknowledge them as individuals when encountering them.

The importance of familiar surroundings was evidenced by JW's refusal to live nearer his children, despite advancing age and their offer of support. Similarly, a small deviation from his usual route meant he became completely lost one day while traveling to an appointment at Moorfields Eye Hospital. His reluctance to ask for help, and hence identify himself as having a visual problem, resulted in him returning home.

Avoidance of potentially difficult situations, which might otherwise have been facilitated by disclosure, nurtured a sharpness of mind for excuses about why he could not be involved in something. This (often desperate) need to avoid disclosure was based ultimately on his fear of losing the respect of others. Examples include:

- refusing to ask for help when struggling to find a friend's house at night and making up an excuse for why he was late to their bridge evening (this incident led to him giving up playing bridge with his friends altogether, since it was always an evening activity; he never told them the real reason for this)

- trying every excuse he could think of to avoid walking with friends along the River Cam one night, but finally being forced to disclose when he had run out of "excuses" (Table 4A). He now thinks he was shy and withdrawn as a child because of his inability to socialize in the same way as other children, although he recognizes that he did not feel this at the time.

JW developed the habit of mentally logging features of an outward journey to aid his return. At home, everything has a place, as he has great trouble finding anything that is not where it should be. JW uses magnification aids when working on the computer. He also has a selection of torches at home, but he would rather avoid attracting attention than use them outside. When young, JW developed a method of using his foot as if it were the end of a white cane to feel his way along the edge of a curb.

JW became an accomplished sportsman, which won him much praise and admiration as a young adult. As well as being enjoyable in itself, this contributed greatly to improving his self-esteem.
Positive situations

Situations or activities that are coped with well 
Table I (Continued)

\begin{tabular}{|c|c|}
\hline Theme & Summary of JW's experience in relation to themes \\
\hline Problematic situations & JW has great difficulty seeing anything in low light, such as: \\
\hline Situations that are particularly difficult & $\begin{array}{l}\text { - finding the keyhole in his front door, which is sufficiently recessed as to not be well-enough } \\
\text { lit } \\
\text { - finding the taxi rank at Liverpool Street station in London, which is undercover so that there } \\
\text { is insufficient light, even during the day, to reflect off the black cabs and make them visible to } \\
\text { him } \\
\text { - locating someone in a café or restaurant where the lighting is "subdued" (Table 2A) } \\
\text { - seeing into shady areas on a sunny day, eg, trying to find a shoe in the footwell of a taxi } \\
\text { (Table 2B). }\end{array}$ \\
\hline
\end{tabular}

\section{The way I see}

Descriptions of phenomenological aspects of seeing

\section{Thoughts on low vision \\ Some philosophical perspectives on vision impairment}

Thoughts on vision research Views on the value of research into ophthalmic disorders

Method or process of diagnosis Details of diagnosis, progression of the condition, and treatment
JW does not feel that his hearing is improved to compensate for his loss of vision. When he is unable to immediately identify something, JW is fascinated by the process of discovering what it is that he is looking at. He is able to articulate various stages of the sense-making process that he goes through when deciphering an image on the computer, for example. Unusually, with his eyes closed and after a period of acclimatization, JW reports seeing complete blackness.

JW is concerned about the inheritability of his condition and how it might affect future generations of his family. He is conscious of his deteriorating vision, both in dim and bright light, but seems accepting of this given his age.

While fully recognizing that research cannot improve his own night blindness, JW is both enthusiastic and optimistic about the possibility that a better understanding of the condition may lead eventually to a cure that would benefit others.

JW's myopia was diagnosed and corrected with refraction at the age of approximately 6 years. His difficulty seeing in the dark was noticed by members of his family, eg, his aunt remarked on how, as a young child, he would feel his way along the wall as he went upstairs to bed, but throughout his life opticians failed to recognize his CSNB. He reports that it was nice to be believed when he was finally diagnosed at the age of 74 years. The diagnosis was a significant turning point in JW's life, as it enabled him to name and thus objectify his visual impairment. This led to him developing the confidence to disclose his condition and to deal with the consequences of disclosure. He continues to be monitored through regular appointments.

Abbreviation: CSNB, congenital stationary night blindness.

had told all the stories he thought were relevant to the way he lives with CSNB. Once this point had been reached, the data and coded themes were viewed from a socionarratology perspective, ${ }^{19}$ in order to consider the broader significance of JW's data. A schematic of the overall analytic process is presented in Figure 3.

Frank ${ }^{19}$ understands the primary work of stories to be a guidance system that helps those who hear stories to select what is worth paying attention to and to consider their selections in an evaluative way. He describes how stories achieve this in terms of a repertoire of "capacities". Therefore, stories explicate troublesome problems (Capacity 1), and in so doing present models for dealing with different kinds of trouble. They open alternative possibilities for individual action and identity (Capacity 2) and, in so doing, bring moral clarity to the consequences of such actions for both characters within the story and receivers of the story; how and how not to act (Capacity 3). Stories are told in order to be echoed in stories yet to be heard, and so to resonate beyond their immediate moment. JW's stories, as illustrated in Tables 2-5, span a lifetime, when viewed through a socionarratology lens show their wider value in arriving at more nuanced accounts of experience to inform vision research and practice.

\section{Results}

The most striking functional aspect of JW's visual impairment was reported by him, and shown through psychophysical testing, to be his greatly reduced capacity to adapt to low light levels. Measuring an observer's detection sensitivity to light as a function of wavelength produces spectral sensitivity curves (Figure 4A and B). Since photoreceptors have characteristic spectral sensitivities, it is possible to infer which photoreceptor type mediates detection from the shape of the measured spectral sensitivity data. Therefore, once a normal subject has become fully dark-adapted by spending 40 minutes in a completely dark room, the spectral sensitivity data (Figure 4A, gray circles) have the rod spectral sensitivity shape (solid line), indicating that rods mediate detection. In contrast, the dark-adapted spectral sensitivity curve for JW (open circles) revealed that he was 30,000 times less sensitive to light compared to normals, and suggests, since 


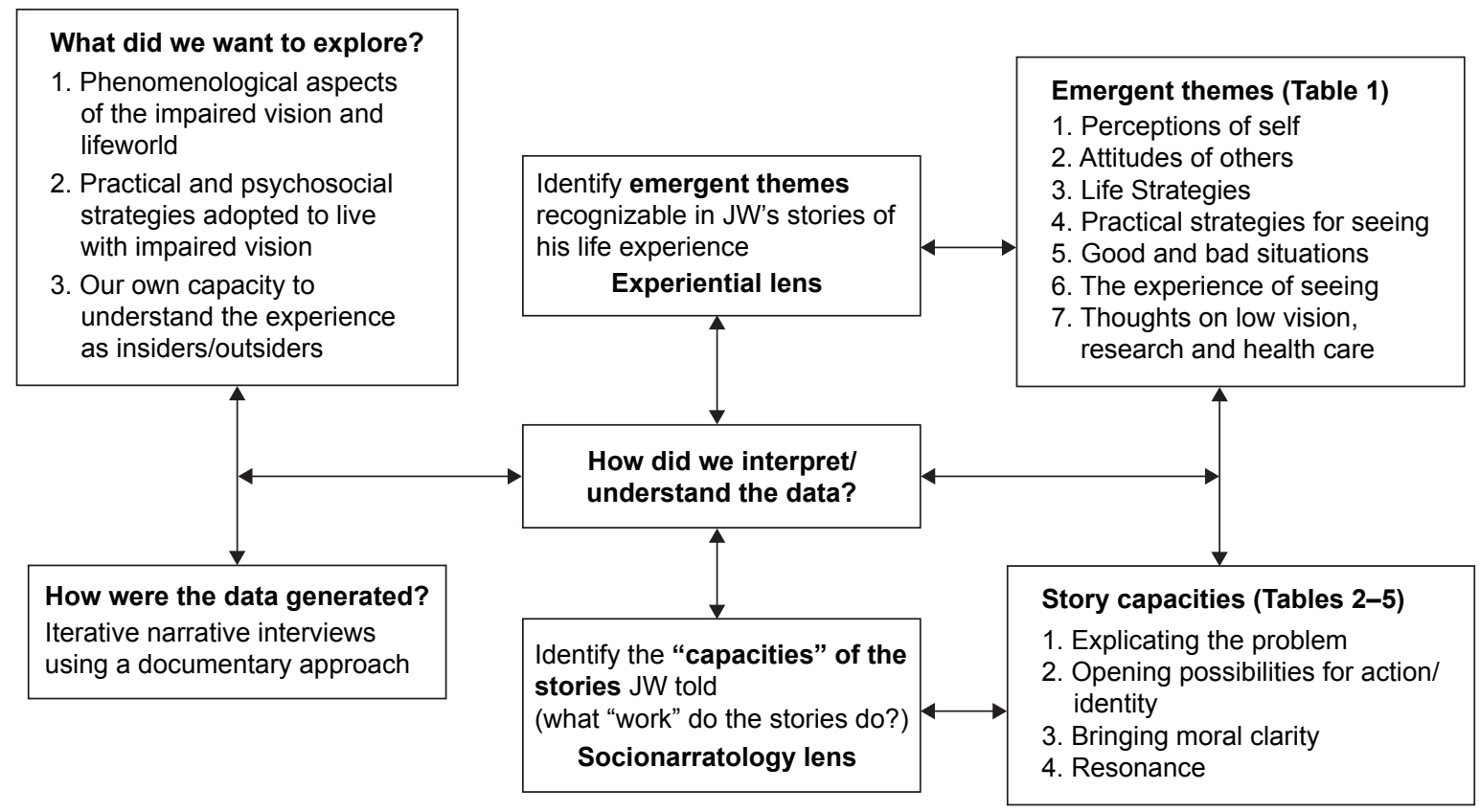

Figure 3 Interpretative framework for JW's interview data.

its shape is consistent with cone-mediated detection (dashed line), that under these conditions JW relies entirely on his cones and has no effective rod vision. These data, then, are effectively a measure of cone and cone OFF-pathway activity, since all mGluR6-mediated circuitry (involving ON bipolar cells) would be nonfunctional in this patient.
Bleaching the retina and taking measurements between 3 and 10 minutes after the bleach, when cones in normal observers have recovered but rods have not, enables cone spectral sensitivity to be investigated in isolation. ${ }^{20}$ Measurements made during this interval, known as the "cone plateau", indicated a substantial loss of cone function for JW,

Table 2 More than just a problem at night

A

JW008 audio 0I I/August 22, 20I 2/00:19:02

In eating places, the fashion has become - subdue the lighting. If I'm on my own, a very helpful waiter, they'll say, "Would you like to follow me, sir, yes, in there". When they're saying "in there", I can't see what they're referring to. To them, they're saying, "In there, look, there's an empty chair there: take that seat". And I'm standing around, thinking, "Where is it? I can't see it".

JW035 audio 040/November 26, 2013/23:44: 10

It was a lovely clear, bright, sunny day, and he [the taxi driver] looked down and saw that my sandal wasn't there. I looked down in the footwell of the taxi at the back. Obviously, there's no light gets down there, or very little light, enough for him to see if there was a sandal there or not. To me, it looked like a black hole. I could have been looking in a hole 20' deep. So that's when I thought, well, you know, it's more than just a problem at night, it's not just night blindness, anywhere where the light is not as good as it should be. And it's made even worse if you're out in the bright sunshine and then looking inside this taxi. He could do it okay, all his rods were working, but mine weren't.

B

JW008 audio 01 I/August 22, 2012/00:06:16

What you need to navigate is a light source, all you need, a little dot of light and then you make for it, you walk towards it.

JW005 audio 008/June 12, 2012/00:21:49

One of the most useful things to someone with my problem is reflections, because I could go from where I was to the next street light, in a straight line, on a dry evening, and walk slap-bang into a parked car - just go straight into it. But when it rains, you've got all this glistening. The lights that were around would be reflected in the cars, so I wouldn't know what sort of car it was, but that would be clearly visible to me.

JW005 audio 008/June I2, 20I 2/00:24:17

The reflections used to travel along the curb. It wouldn't throw out enough light to light my way, but it would throw out enough light for me to be able to navigate better.

JW0I7 audio 02I/November 14, 2012/00:13:44

The more I could remember of the journey out, then the easier it would be to get back. So I just developed the habit of almost plotting my return trip on my outward trip. And I mean it: after a while, it became second nature. And that was very helpful. 
Table 3 No labels for it

A

JW003 audio 006/June I2, 20I 2/00:09:4 I

I couldn't understand why everybody else was dashing out the back door down to the shelter and here was I stood like a statue, because really it $[\ldots]$ if you imagine what it was like for me in those circumstances, it's like standing there with my eyes closed: that, that is what I get - standing with my eyes closed.

JW003 audio 006/June 12, 2012/00:18:53

I used to feel, why can't I be as hurried and urgent as everybody else is, getting to that shelter? Because if a bomb were to drop, I was slowing everybody down.

JW003 audio 006/June 12, 2012/00:14:54

Now that's the first time that I ever worried about my night blindness. I couldn't put a name to it; I just worried about the fact that I had to B get from the house to the shelter in pitch-dark.

\section{JW00I audio 002/April 17, 2012/01:29:18}

I mean the first time you become aware that you have a visual problem is the time when you realize that somebody else can see a lot better than you, but you've got to realize that, and you've got to have the mental capacity to work that out. And at the age of 5, 6, you don't work that out. You take the world as it is, and you assume it's the same for everybody.

JW003 audio 006/June 12, 20I 2/00:28:29

At that stage, I was aware of the fact that I couldn't see at night. Now that was all. I had no labels for it, I never even tried to explain it to anyone else; I was rather, rather withdrawn; I'd tend to just put up with things and solve them as best I could.

JW007 audio $010 /$ June I2, 20I2/I2:32:02

The fact is that my parents came out in the open about my myopia. They said, "He's got bad eyesight", meaning my myopia, so they talked about it with people they knew, therefore I had no problem with that. But my parents didn't talk about my night blindness 'cause they didn't know about my night blindness. I came out of nowhere, because of those blessed recessionary genes, recessive genes. They didn't talk about it, so I didn't talk about it.

whose minimum detectable radiance is some 300 times greater than that for normals (Figure 4B). Since foveal structure and the retinal pigment epithelium were relatively intact (Figures 1 and 2), it is likely that this reduced cone function resulted primarily from the loss of mGluR6-mediated ON cone bipolar function. This may also account for the slower rate of dark adaptation observed in JW, whose cone response is still about ten times lower than its prebleach, dark-adapted level during the cone-plateau phase (Figure $4 \mathrm{~A}$ and $\mathrm{B}$ ). The responses represented in Figure 4A and B seem likely to be mediated predominantly by $\mathrm{L} / \mathrm{M}$ cones and cone OFF pathways, as there was little evidence of S-cone activity.

Table 4 You keep it to yourself

\section{A}

JW007 audio 0 I0/June I2, 20I 2/I 2:34:00

[...] so we all had a meal out, all jolly end-of-term-ish, you know, and one of them said, "Let's walk along the Backs". Now, that simply meant walking along the river. This is at night [JW sighs]. Oh my God, how am I gonna cope, what am I gonna do? l'll walk straight into the river. I think, there's got to be a way round this: "Well, do we have to walk along the Backs, "cause I mean I quite like walking through town?". "Oh no, it'll be fun down there, walking through the Backs". [JW sighs again] "Okay". So we walked out of the well-lit-up area of the town towards the Backs, the lighting became worse and worse, and suddenly stopped, like that. I knew the Backs were there, "cause the lighting had stopped. I thought, "I don't know what to do. I do not know what to do". I stood still; I just stood stock-still, and the rest of them went walking on. "Come on, ****”, I said, “I can't". "What do you mean, you can't?" “I can't see”. "You can't see? You've been all right all [...]”. "I know, it's nighttime, it's dark, and I can't see when it's dark, okay?" I, I was quite annoyed with them actually, for making me have to admit this. "I'll just have to hang onto somebody". Two of the girls said, "Oh you hang onto me, hang onto me!" They were queuing up to put their arms through mine [JW laughing]. No, no shortage of volunteers at all, no awkwardness. "Now, l'm going to ask all of you a favor: please, please, please don't put me to the test. Don't walk up to the river and say, 'He'll back off". I said, "I won't back off, I'll walk into the river". I B must have said it with such conviction they didn't try that one on, because I would have done: l'd have walked into the river.

\section{JW0 audio 0402/July 16, 2013/I6:47:00}

When I took that girl out and we had that embarrassment in the cinema, I wanted to be well thought of. I wanted her to think, "Oh, he's a bit of all right, isn't he? He's, he's nice, he's nice, he's 'normal”. And I wasn't normal, so you keep it to yourself, don't you? - that. I mean, for all I know she went home and said to her parents, "D'you know, he came in the wrong row, he came right up to the middle in the wrong row, and then he had to go all the way back and push past all these people's knees, and some of them were being very rude about it". And for all I know, that's how she took it. I don't know. But in my mind, I used to think, "I bet that's what she's saying now; make me feel a proper idiot. I don't think I want to go out with her anymore, because she knows my little secret. Her respect for me is probably gone". I don't know if it was: I put two and two together, and I might have got five, who knows. It seemed to me the, the safest way, the safest way, and the more certain way is to keep it to myself. 
Table 5 My dark is not the same as their dark

\section{A}

\section{JW035/November 14, 20 I 2/22:49:3 I}

In those days, nobody actually spelled it out to you that you weren't as good as anybody else, but you didn't feel whole, you didn't feel a whole person, 'cause parts of you were missing. And the parts of you were missing was perfect vision or perfect night vision.

\section{2:49:56}

[...] so you were missing something, so you weren't as good as the people that could see properly, and that's how they took it as well.

\section{2:34:47}

It goes back to the day when I was seven or eight, when I was in primary school, and being the only one with glasses, and some of the children, being very unkind, would call me "four-eyes".

\section{2:35: 10}

[...] so as soon as I became identified with having a visual problem, and you can't not be identified if you're wearing glasses, then you get the, the "four-eyes" thrown at you.

\section{2:35:35}

[...] and I just got in the habit, of not wanting to let on that not only did I have to wear glasses during the day, but I also couldn't see at night. 22:35:56

B

[...] it just became ingrained in me: you don't tell anybody. And I never sat down and rationalized it; it just became what I did.

\section{JW00I/April 17, 2012/13:14:08}

I've given no end of people, I've said to them, "I can't see at night. I can't see when it's dark". They tend to say to me, "Well, neither can I".

C

They don't realize that my dark isn't the same as their dark; I mean, dusk can be my dark, but it's not their dark.

JW035/November 14, 20I2/22:42:15

If you said to me you can have one wish regarding the way you dealt with your visual problems, I think I would come to terms with it and say

I wish I was up-front with everybody about it, on every occasion when it happened.

\section{2:43:18}

I regret that like anything, and part of the regret is that it was something that I could have done something about. I couldn't do anything about my, my visual problems, but I could have done something about that. Which would have meant that all the emotional upsets I had trying to work things out and how was I gonna overcome this and how was I gonna keep it from this one - all those could have been avoided. So I would say to anybody, if you've got a disability, be up-front about it.

JW's cone function was investigated further by measuring his temporal acuity or CFF (ie, determining the highest rate of flicker that he can just detect). Characteristic psychophysical measurements of CFF as a function of radiance were made under conditions that revealed mainly L-cone function (Figure 4C) or S-cone function (Figure 4D). JW's L-cone CFF data (open circles) indicated a loss in CFF that increased with increasing irradiance, which is indicative of an impaired capacity for light adaptation compared to normals (gray circles). JW's S-cone CFF data revealed that JW first detects flicker at a radiance over 100 times greater than that for normal subjects (Figure 4D). This markedly impaired S-cone function is consistent with JW's abnormal S-cone ERG ${ }^{12}$ and with the loss of the primary S-cone pathway via mGluR6-mediated ON bipolar cells. ${ }^{21}$ When tested using the Farnsworth-Munsell 100-hue test, JW showed a tritanope-type profile of impaired chromatic discrimination indicative of a severe S-cone deficit (total error score 264). However, he reported no particular problems with his color vision in everyday life, other than finding it easier to read black print on a green or blue background than against red or indigo. Other observers with this deficit have not been shown to be completely S-cone blind (ie, tritanopic) either, ${ }^{22}$ and in these cases, the residual S-cone function must be served by pathways that are independent of the ON system, eg, via OFF pathways, perhaps by way of $\mathrm{H} 2$ horizontal cells. ${ }^{23,24}$ These connections may also underlie the phenomenological reports by JW that he was unable to differentiate the blue, flickering S-cone target from its orange surround, but was aware of "darker blotches", predominantly in the target area, whose opacity he could manipulate by changing the target flicker rate.

The practical impact of JW's lack of rod-pathway functionality on everyday life means that he not only has great difficulty seeing at night but also additionally has severe problems at dawn and dusk and in situations that are dimly lit (Table 2). He particularly describes experiencing difficulty seeing into darker areas scattered throughout a brighter natural scene (Table $2 \mathrm{~A}$ ), and this is probably due to a combination of absent rod vision, greatly reduced cone function, and his slower rate of dark adaptation.

In dark environments, JW reports only being able to detect highlights in the scene and has developed a number of strategies for dealing with the absence of shades of gray within his visual experience of scotopic conditions. These include the use of reflections, point sources of light, and mental maps to help him navigate (Table 2B and Video 1). 
A Rod (dark-adapted)

A Rod (dark-adapted) spectral
sensitivity

A Rod (dark-adapted)

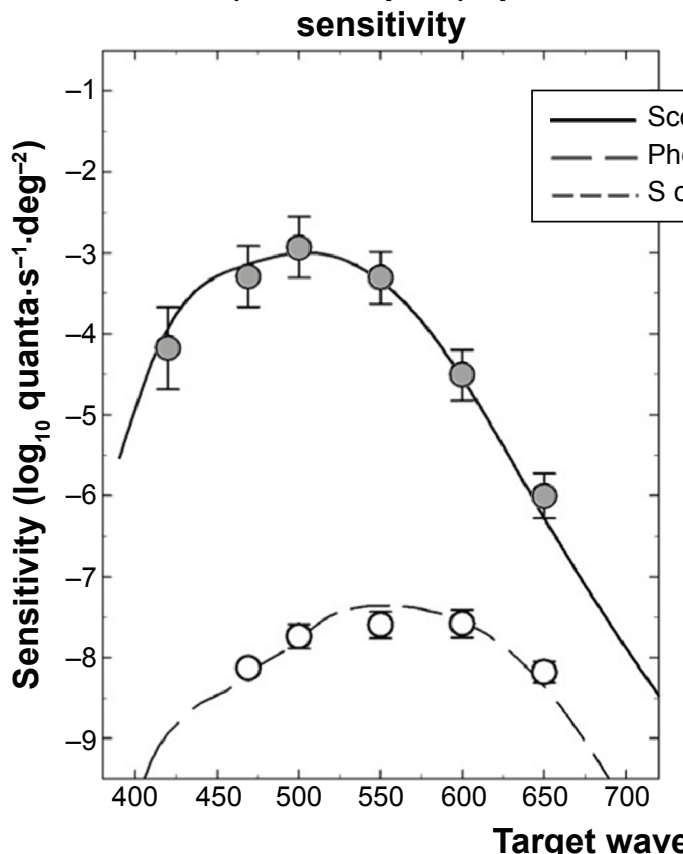

Target wavelength $(\mathrm{nm})$
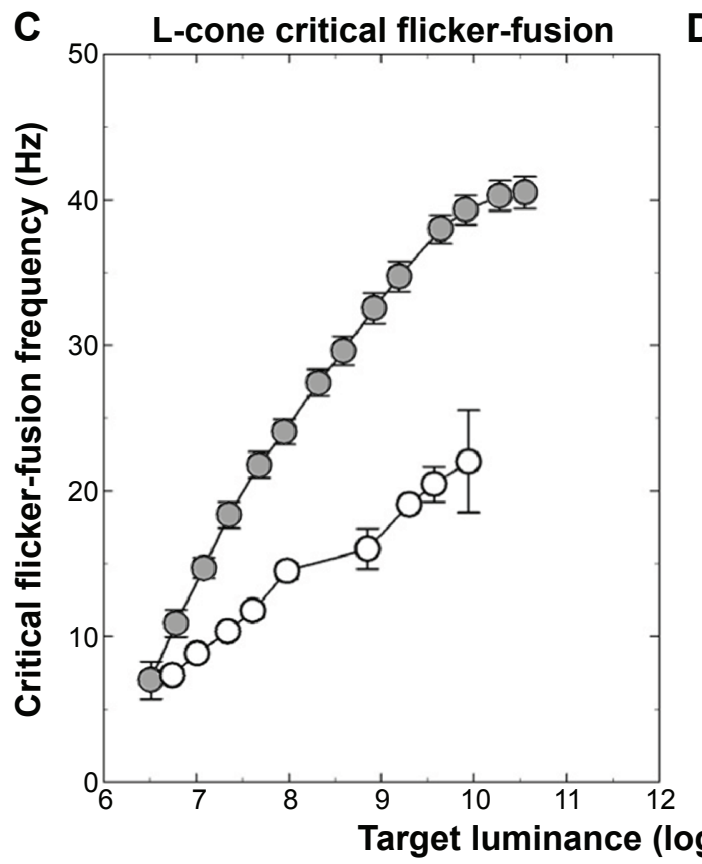

D S-cone critical flicker-fusion

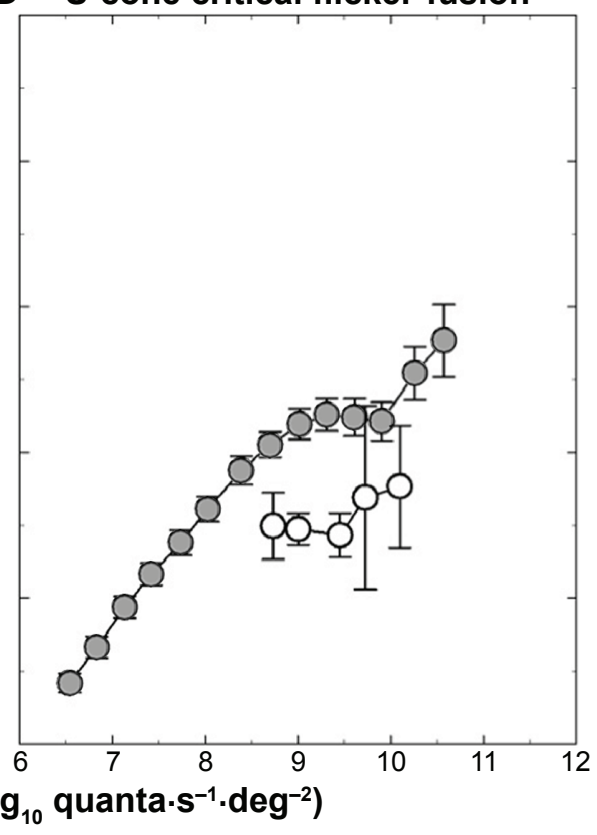

Figure 4 Spectral sensitivity and critical flicker-fusion measurements.

Notes: (A) Dark-adapted spectral sensitivity measurements plotted as a function of wavelength. JW (open circles) and normals ( $\mathrm{n}=4$, gray circles). Measurements were made after 40 minutes of adaptation in complete darkness, after which rod function can usually be observed in isolation from cone function in normal control observers. For the spectral sensitivity measurements, subjects adjusted the intensity of a I Hz sinusoidal flickering light (presented at a series of wavelengths and at the fixed maximum stimulus modulation of $92 \%$ ) to find the minimum intensity at which the flicker could just be detected. JW was unable to see the small, eccentric target normally used for these measurements, so a larger $10^{\circ}$-diameter target was presented centrally behind a diffuser for both him and the control subjects. Other procedural details have been published elsewhere. ${ }^{13}$ All psychophysical measurements for JW were conducted on his right eye. (B) Postbleach spectral sensitivities plotted as a function of wavelength. Measurements were made between 3 and 10 minutes following intense white bleach during the cone plateau, when in the normal observer the cones have recovered, but rods have not. Data for JW (open circles) and normals ( $\mathrm{n}=4$, gray circles) are shown. The same target was used as for the dark-adapted measurements. Other procedural details have been published elsewhere. ${ }^{13}$ (C) L-cone critical flicker-fusion frequencies plotted as a function of the mean log radiance of a $650 \mathrm{~nm}$ flickering target presented on a $48 \mathrm{I} \mathrm{nm}$ background of $8.26 \mathrm{log}$ quanta. $\mathrm{s}^{-1} \cdot \mathrm{deg}^{-2}$. Data for JW (open circles) and normals ( $\mathrm{n}=12$, gray circles). To make the critical flicker-fusion measurements, the subject adjusted the flicker frequency of a sinusoidally flickering light (presented at the fixed maximum stimulus modulation of $92 \%$ ) to find the frequency at a series of mean radiances at which the flicker just disappeared. Procedural details have been published elsewhere. ${ }^{14}$ (D) S-cone critical flicker-fusion frequencies plotted as a function of the mean log radiance of a $440 \mathrm{~nm}$ flickering target presented on a $620 \mathrm{~nm}$ background of $8.26 \mathrm{log}$ quanta $\cdot \mathrm{s}^{-1} \cdot \mathrm{deg}^{-2}$. Data for JW (open circles) and normals ( $\mathrm{n}=12$, gray circles). Procedural details have been published elsewhere. ${ }^{14}$ 
JW's difficulty in dark conditions is not surprising, given his lack of rod perception, but what is less predictable is the impact that this has had on his sense of self and his relation to the world. Recognizing his difficulty but with no knowledge of the condition of NB, JW, like many people with a disability that is not apparent to others, spent much of his life ensuring that his vision impairment remained concealed. ${ }^{25}$ The lengths to which he would go to evade disclosure culminated in his often avoiding social situations and from a young age made him withdrawn and quiet. But why is disclosure itself such an issue, and why does the possibility of forced disclosure cause such distress? For JW, the answers are rooted in his early life.

JW can recall in minute detail the physicality of a frightening dash to the air-raid shelter during the Second World War (Table 3A) in what was for him "pitch-dark", although there was evidently sufficient ambient light for others to see their way without difficulty. While acutely aware of the debilitating effect of his NB in such circumstances, JW had no language with which to articulate the cause of his difficulties (Table 3B), creating a secondary problem that continued until his diagnosis.

Having developed a habit of nondisclosure from this early age, JW was confronted with occasions later in life when he had no option but to disclose, as when walking through Cambridge one night with friends (Table 4A). What is particularly striking about this account is his use of the word "admit", suggesting that JW attributed fault to his inability to see. The prospect of forced disclosure of such private information can clearly cause great anxiety, and some 15 months into the study JW finally identified the problem as fear of losing the respect of others (Table 4B and Video 2).

With hindsight, JW attributes these feelings of inferiority partly to being teased about his myopia at school (Table 5A) and partly to the lack of awareness of NB as a condition. Despite his reluctance to disclose, however, JW tried many times to seek professional advice (Table 5B) but went undiagnosed until being seen at Moorfields Eye Hospital at the age of 74 years. Now, and partly through his involvement in this study, he is not only more willing to disclose but has also developed a confidence in the value of his personal experience of vision loss (Table 5C).

\section{Discussion}

Previous studies have evidenced a dysfunction of S-cone ON pathways in CSNB caused by GRM6 mutation, ${ }^{4,7,12}$ and further that a putative S-cone OFF pathway, which co-opts ON bipolar cells, is also likely to be affected. ${ }^{24}$ The age of this patient, however, may preclude conclusions being drawn about this S-cone OFF pathway, since it, like the ON pathway, is thought to deteriorate more rapidly than L- and M-cone pathways with age. ${ }^{26}$ The residual S-cone function observed in JW suggests that an alternative, nonglutaminergic S-cone pathway remains intact, possibly via $\mathrm{H} 2$ horizontal cells and OFF L- and M-cone pathways, but certain perceptual phenomena reported during psychophysical testing require further investigation.

Research involving subjective accounts of vision loss has often focused on quality-of-life issues following eye surgery or onset of vision impairment, but most has adopted structured or semistructured interviews. ${ }^{27,28}$ While clearly a resource-heavy methodology, the use of in-depth, openended, participant-led interview and an analytic approach based on established methods of narrative inquiry ${ }^{11,18,29,30}$ and documentary-filmmaking practices can enable the researcher to access aspects of the participant's experience that are unlikely to be revealed through conventional interviewing techniques or mediating questionnaires. The immediacy of the interview technique, together with the objectivity that the camera lens and timescale facilitated, allowed JW to reflect on and reassess his perspective on the events and responses in his life within the context of his vision loss. This process also led to him feeling more confident in the value of his visually impaired life experience. In dialogue with psychophysical and clinical measures, the richness of this patient testimony enables a fuller understanding of the everyday experience of a condition by both researcher and patient. In addition, given the ubiquitous nature of film as a medium through which we routinely access the stories and minds of others, filmmaking techniques offer a means of communicating such findings to a broad audience, including researchers on both sides of the traditional qualitative/quantitative divide. It is hoped that the experiential, patient-centered emphasis of this study will encourage informed appreciation of the practical, social, and psychological implications of rare visual disorders and the value of patient involvement in developing targeted approaches to the design of services, environments, and research.

\section{Acknowledgments}

JC would like to acknowledge the generous contribution and commitment of JW, without whose involvement this study would not have been possible. She would also like to thank Bruce Henning for his thoughtful comments and advice on earlier drafts of this manuscript and Vy Luong for collection of psychophysical data. None of these received compensation 
for their contribution. This research was funded by the Leverhulme Trust Early Career Fellowship scheme (ECF-2011167), Moorfields Eye Hospital Special Trustees (ST 1107 C), and the National Institute for Health Research (NIHR) Biomedical Research Centre at Moorfields Eye Hospital NHS Foundation Trust, and University College London Institute of Ophthalmology (BMRC 096 and BRC2_017). The views expressed are those of the authors and not necessarily those of the NHS, the NIHR, or the Department of Health. University College London Institute of Ophthalmology was the study sponsor and was involved in the design and conduct of the study, the collection, management, analysis, and interpretation of the data, and in the preparation, review, and approval of this manuscript. The funders were not involved in any of these activities.

\section{Disclosure}

The authors report no conflicts of interest in this work.

\section{References}

1. Fitzke FW. Clinical psychophysics. Eye (Lond). 1988;2 Suppl: S233-S241.

2. Gardiner JC, Webb TR, Kanuga N, et al. X-linked cone dystrophy caused by mutation of the red and green cone opsins. Am J Hum Genet. 2010;87:26-39.

3. Dryja TP. Molecular genetics of Oguchi disease, fundus albipunctatus, and other forms of stationary night blindness: LVII Edward Jackson Memorial Lecture. Am J Ophthalmol. 2000;130(5):547-563.

4. Zeitz C, Robson AG, Audo I. Congenital stationary night blindness: an analysis and update of genotype-phenotype correlations and pathogenic mechanisms. Prog Retin Eye Res. 2015;45:58-110.

5. Dryja TP, McGee TL, Berson EL, et al. Night blindness and abnormal cone electroretinogram $\mathrm{ON}$ responses in patients with mutations in the GRM6 gene encoding mGluR6. Proc Natl Acad Sci U S A. 2005;102(12): 4884-4889.

6. Hashimoto $\mathrm{T}$, Inazawa $\mathrm{J}$, Okamoto $\mathrm{N}$, et al. The whole nucleotide sequence and chromosomal localization of the gene for human metabotropic glutamate receptor subtype 6. Eur J Neurosci. 1997;9:1226-1235.

7. Masu M, Iwakabe H, Tagawa Y, et al. Specific deficit of the ON response in visual transmission by targeted disruption of the mGluR6 gene. Cell. 1995;80:757-765.

8. Lee BB, Martin PR, Grünert U. Retinal connectivity and primate vision. Prog Retin Eye Res. 2010;29:622-639.

9. Solomon SG, Lennie P. The machinery of colour vision. Nat Rev Neurosci. 2007;8(4):276-286.
10. Todres L, Galvin K, Dahlberg K. Lifeworld-led healthcare: revisiting a humanising philosophy that integrates emerging trends. Med Health Care Philos. 2007;10:53-63.

11. Polkinghorne DE. Narrative configuration in qualitative analysis. Int J Qual Stud Educ. 1995;8(1):5-23.

12. Sergouniotis PI, Robson AG, Li Z, et al. A phenotypic study of congenital stationary night blindness (CSNB) associated with mutations in the GRM6 gene. Acta Ophthalmol. 2012;90:e192-e197.

13. Stockman A, Plummer DJ, Montag ED. Spectrally-opponent inputs to the human luminance pathway: slow $\mathrm{M}$ and $-\mathrm{L}$ cone inputs revealed by intense long-wavelength adaptation. $J$ Physiol. 2005;566:61-76.

14. Stockman A, Henning GB, Michaelides M, et al. Cone dystrophy with "supernormal" rod ERG: psychophysical testing shows comparable rod and cone temporal sensitivity losses with no gain in rod function. Invest Ophthalmol Vis Sci. 2014;55(2):832-840.

15. Kelly T, Howie L. Working with stories in nursing research: procedures used in narrative analysis. Int J Ment Health Nurs. 2007;16:136-144.

16. Hall JM, Powell J. Understanding the person through narrative. Nurs Res Pract. 2011;Article 293837.

17. Transana [website on the Internet]. 2015. Available from: http://www. transana.org. Accessed March 14, 2012.

18. Bruner J. Actual Minds, Possible Worlds. Cambridge (MA): Harvard University Press; 1985.

19. Frank AW. Letting Stories Breathe: A Socio-narratology. Chicago: University of Chicago Press; 2010.

20. Hecht S, Haig C, Wald G. The dark adaptation of retinal fields of different size and location. J Gen Physiol. 1935;19:321-337.

21. Mariani AP. Bipolar cells in monkey retina selective for the cones likely to be blue-sensitive. Nature. 1984;308:184-186.

22. Neitz J, Mauke MC, Neitz M. A gene mutation interrupts color constancy but not colour discrimination. J Vis. 2009;9:68.

23. Dacey DM. Parallel pathways for spectral coding in primate retina. Annu Rev Neurosci. 2000;23:743-775.

24. Dacey DM, Crook JD, Packer OS. Distinct synaptic mechanisms create parallel S-ON and S-OFF color opponent pathways in the primate retina. Vis Neurosci. 2014;31(2):139-151.

25. Senra H, Oliveira RA, Leal I. From self-awareness to self-identification with visual impairment: a qualitative study with working age adults at a rehabilitation setting. Clin Rehabil. 2011;25(12):1140-1151.

26. Shinomori K, Werner JS. Aging of human short-wave cone pathways. Proc Natl Acad Sci U S A. 2012;109(33):13422-13427.

27. McLean RJ, Windridge KC, Gottlob I. Living with nystagmus: a qualitative study. Br J Ophthalmol. 2012;96:981-986.

28. Bennion AE, Shaw RL, Gibson JM. What do we know about the experience of age related macular degeneration? A systematic review and meta-synthesis of qualitative research. Soc Sci Med. 2012;75: 976-985.

29. Moore LW, Miller M. Older men's experiences of living with severe visual impairment. $J$ Adv Nurs. 2003;43(1):10-18.

30. Cross V, Shah P, Glynn M, Chidrawar S. ReGAE 5: can we improve the surgical journey for African-Caribbean patients undergoing glaucoma filtration surgery? Some preliminary findings. Clin Ophthalmol. 2009; $3: 1-12$. 


\section{Supplementary materials}

Video $1(\mathbf{1 ~ m}) \mathrm{JW}$ on using reflections to aid navigation (.mov, with sound).

This sequence presents an interpretation of the way JW navigates when ambient illumination is below his sensitivity threshold. Shot at night using the camera to present his point of view, and using his voice-over (Table 2B), the importance of highlights in the visual field is made evident, both as emitted and as reflected light. The reflective quality of surfaces, especially when wet, is shown to be particularly useful. Viewable with QuickTime Player.

Video 2 (1 m 25 s) JW on reluctance to disclose (.mov, with sound).

JW relays a story in which he clearly articulates his anxiety about the possible consequences of disclosing his diagnosis of night blindness. This interview was recorded on July 6, 2013, at his home. JW gave written consent for video footage of him to be used.

\section{Materials and methods Psychophysics procedures}

Measurements were made using two standard Maxwellianview systems: one for the cone (photopic) experiments, and the second for the rod (scotopic) experiments. Both systems allow the projection of lights directly onto the observer's retina. Apart from the stimuli, the room was otherwise dark. The wavelengths of the target and background were selected by interference filters (Ealing or Oriel), and the radiance in each channel was controlled by a combination of neutral-density filters (Oriel), and by the rotation, under computer control, of a circular, variable-neutral-density filter (Rolyn Optics, Covina, CA, USA). During photopic measurements, the image of the source, focused in the plane of the subject's pupil, was always less than the minimal pupil size, such that retinal illumination was not affected by pupil size. The position of the observer's head was maintained by a hardened dental wax impression, and could be adjusted in three dimensions to locate the exit pupil of the optics in the center and in the plane of the observer's pupil. During scotopic measurements, since the congenital stationary night-blindness observer was unable to see the usual stimulus in Maxwellian view, a larger target was projected onto a diffuser screen and the movement of the subject's head was restricted using a chin rest. The subject was regularly reminded to fixate at the chosen location. This setup is used routinely with younger subjects. Full details of the apparatus have been published elsewhere. ${ }^{1,2}$

All observers light-adapted to the stimuli for 3 minutes before L-cone and S-cone CFF measurements were made.
Before rod measurements were taken, the subject first dark-adapted in total darkness for 40 minutes. For all measurements, the subjects interacted with the computers that controlled the apparatus by means of an eight-button keypad, receiving information and instructions via tones and a computer-controlled voice synthesizer, as well as from the researcher. To set the CFF, the subject adjusted the flicker frequency of a sinusoidally flickering light (at the fixed maximum stimulus modulation of $92 \%$ ) to find the frequency at which the flicker just disappeared. Each set of psychophysical measurements was repeated three times. The plotted data are the mean values and standard error of the three repeats.

\section{Stimuli}

\section{Rod stimuli}

The subject was unable to see the usual flickering stimulus of $5.74^{\circ}$ in diameter presented at an eccentricity of $10^{\circ}$ in the temporal retina, so instead a target of $10^{\circ}$ in diameter was presented centrally projected on a diffuser lens. The subject was asked to fixate eccentrically at an optimal position and to maintain that fixated position throughout the test without the aid of a fixation light or dental impression. The stimulus-flicker frequency was $1 \mathrm{~Hz}$, and no background was present. By convention, we use scotopic trolands for the rod measurements, rather than quantal units. Cone detection was achieved by restricting measurements to the cone plateau: between 3 and 10 minutes following an intense white bleach when cones have recovered, but rods have not.

\section{L-cone stimuli}

A sinusoidal flickering target of $4^{\circ}$ diameter in visual angle and $650 \mathrm{~nm}$ in wavelength was presented in the center of a $9^{\circ}$ diameter background field of $481 \mathrm{~nm}$. The fixation point was chosen by the patient. The $481 \mathrm{~nm}$ background, which delivered $8.29 \log$ quanta $\cdot \mathrm{s}^{-1} \cdot \mathrm{deg}^{-2}$ at the cornea $\left(1.42 \log _{10}\right.$ photopic trolands or $2.58 \log _{10}$ scotopic trolands), mainly served not only to suppress the rods but also to selectively desensitize the $\mathrm{M}$ cones at lower target radiances. The primary target wavelength of $650 \mathrm{~nm}$ was chosen to favor detection by cones rather than rods. For the CFF measurements, its intensity was varied from 6.5 to $11.5 \log _{10}$ quanta $\cdot \mathrm{s}^{-1} \cdot \mathrm{deg}^{-2}$. These conditions isolate the L-cone response over most of the $650 \mathrm{~nm}$-intensity range, but at high intensities, the $\mathrm{M}$ cones are also likely to contribute to flicker detection.

\section{S-cone stimuli}

A flickering target of $4^{\circ}$ in diameter and $440 \mathrm{~nm}$ in wavelength was presented in the center of a $9^{\circ}$ diameter 
background field of $620 \mathrm{~nm}$. The fixation point was chosen by the patient. The $620 \mathrm{~nm}$ background field, which was fixed at $11.41 \log _{10}$ quanta $\cdot \mathrm{s}^{-1} \cdot \mathrm{deg}^{-2}$, selectively desensitized the $\mathrm{M}$ and $\mathrm{L}$ cones, but had comparatively little direct effect on the $\mathrm{S}$ cones. For normal observers, this field isolates the S-cone response to a $440 \mathrm{~nm}$ target up to a radiance of approximately $10.5 \log _{10}$ quanta $\cdot \mathrm{s}^{-1} \cdot \mathrm{deg}^{-2} \cdot{ }^{1,2}$ Above $10 \log _{10}$ quanta $\cdot \mathrm{s}^{-1} \cdot \mathrm{deg}^{-2}$, the $\mathrm{M}$ cones contribute to flicker detection. For the CFF measurements, the $440 \mathrm{~nm}$ target radiance was varied from 6.3 to $11 \log _{10}$ quanta $\cdot \mathrm{s}^{-1} \cdot \mathrm{deg}^{-2}$.

\section{Calibration}

The radiant fluxes of test and background fields were measured at the plane of the observer's entrance pupil with a UDT Instruments radiometer that had been calibrated by the manufacturer against a standard traceable to the National Bureau of Standards and cross-calibrated by us. Neutral-density filters, fixed and variable, were calibrated in situ and field wavelengths used. Interference filters were calibrated in situ with a spectroradiometer (Gamma Scientific, San Diego, CA, USA).

For scotopic measurements with the diffuser, the UDT radiometer was placed at the position of the observer's pupil and pointed at the diffuser. Since we do not know the precise retinal illumination from such a calibration, the data provide only relative measures of quantal sensitivity and are plotted as estimated absolute values in Figures 4A and B based on thresholds and calibrations made in Maxwellian view and with the diffuser in control subjects.

\section{Qualitative procedures}

\section{Theoretical and personal framework}

Two areas of personal experience underlie this study. The first is that the interviewer has a rare cone-rod dystrophy, which although congenital went undiagnosed until the age of 32 years. This late diagnosis meant that they operated and thought of themselves as a sighted person for most of their life, despite considerable sight loss. The invisibility of this sight-impaired status allowed them to appreciate some of the effects and consequences of being visually impaired within a sighted society. We believe this insight has proved extremely valuable in establishing an environment in which research participants feel they can speak freely about their own experiences of reduced vision. While recognizing the potential advantage of the researcher's sight-impaired experience, however, it is equally important and useful to set this particular insight within the broader framework of our human capacity to understand and empathize with the experience of others. To this end, we have at all times maintained and made explicit an awareness of potential bias and its consequences at every level of the research process, including patient selection, data generation and gathering through interview technique/style, identification and coding of stories, and the editing and presentation of what are considered salient findings.

The decision to adopt a narrative-driven qualitative approach to the study was based partly on the evident importance of stories as the means by which people apprehend and communicate meaning about their lives, and partly on the professional interviewing experience of one of the researchers. As a documentary filmmaker, their interview technique relies upon establishing trusting relationships with participants who are then better able to speak about and reflect on their life experiences. It is through the development of such a relationship that JW was able to relay the events and details in his life that were relevant to his impaired vision. It was also this relationship that meant he could then engage in discussion about emerging themes and their relative importance to him.

\section{Recruitment of participants}

The findings presented here form part of a broader study for which nine participants were recruited across a range of retinal disorders, each of which results in a patient's consciousness being deprived of sensory data in a different but characterized way. All participants came through the Medical Retina Clinic at Moorfields Eye Hospital and were registered as either blind or sight impaired. None was paid a stipend.

Patient information sheets were prepared in Royal National Institute for the Blind clear print and on audio compact disc. The charity RP [retinitis pigmentosa] Fighting Blindness was consulted on the content of these documents, and we are grateful for their helpful suggestions. The study was explained to potential participants in person at their home, and a 3-week period of consultation was then scheduled prior to consent being sought. Consent was obtained in the presence of a friend if required to aid signature; audio recording of the consent process was also done where appropriate.

\section{References}

1. Stockman A, MacLeod DI, Lebrun SJ. Faster than the eye can see: blue cones respond to rapid flicker. J Opt Soc Am A. 1993;10:1396-1402.

2. Stockman A, Plummer DJ. Color from invisible flicker: a failure of the Talbot-Plateau law caused by an early "hard" saturating nonlinearity used to partition the human short-wave cone pathway. Vis Res. 1998;38. 3703-3728. 


\section{Publish your work in this journal}

Clinical Ophthalmology is an international, peer-reviewed journal covering all subspecialties within ophthalmology. Key topics include: Optometry; Visual science; Pharmacology and drug therapy in eye diseases; Basic Sciences; Primary and Secondary eye care; Patient Safety and Quality of Care Improvements. This journal is indexed on

Submit your manuscript here: http://www.dovepress.com/clinical-ophthalmology-journal
PubMed Central and CAS, and is the official journal of The Society of Clinical Ophthalmology (SCO). The manuscript management system is completely online and includes a very quick and fair peer-review system, which is all easy to use. Visit http://www.dovepress.com/ testimonials.php to read real quotes from published authors. 